\title{
Yes-associated protein (YAP) predicts poor prognosis and regulates progression of esophageal squamous cell cancer through epithelial-mesenchymal transition
}

\author{
YAN QU, LIN ZHANG, JIANBO WANG, PENGXIANG CHEN, YIBIN JIA, CONG WANG, \\ WENJING YANG, ZHIHUA WEN, QINGXU SONG, BINGXU TAN and YUFENG CHENG \\ Department of Radiation Oncology, Qilu Hospital of Shandong University, Jinan, Shandong 250012, P.R. China
}

Received December 3, 2018; Accepted June 27, 2019

DOI: $10.3892 /$ etm.2019.7896

\begin{abstract}
The impact of yes-associated protein (YAP) on the prognosis of patients with esophageal squamous cell cancer (ESCC) and its mechanism of action has seldom been reported. In the present study, the role of YAP on the prognosis of patients with ESCC and the mechanism of action of YAP in promoting the progression of ESCC was investigated. Tumor tissue samples from patients with ESCC were collected and the level of YAP expression was detected using immunohistochemical staining. In addition, YAP was knocked-down in ESCC cell lines and the effects on cell migration and invasion were examined. The expression levels of vimentin, $\mathrm{N}$-cadherin, and E-cadherin were further investigated to examine the association between YAP and epithelial-mesenchymal transition (EMT). Results showed that overexpression of YAP was associated with larger lymph node metastasis and poor disease-free survival and overall survival. Compared with patients in early stage ESCC, the association was more significant in patients with late stage ESCC. Univariate and multivariate analyses further indicated that YAP expression could be an independent prognostic factor for ESCC. Downregulation of YAP inhibited cell migration and invasion. Western blot analysis showed that when YAP was knocked down, expression levels of vimentin and $\mathrm{N}$-cadherin were reduced, whereas that of E-cadherin was increased. In conclusion, the results indicates that YAP expression level could be a novel marker for predicting the prognosis of patients with ESCC, and YAP-promoted tumor migration and invasion might be through EMT in ESCC.
\end{abstract}

Correspondence to: Professor Yufeng Cheng, Department of Radiation Oncology, Qilu Hospital of Shandong University, 107 West Wenhua Road, Jinan, Shandong 250012, P.R. China E-mail: qlchengyf@163.com

Key words: esophageal squamous cell cancer, yes-associated protein, overexpression, prognosis, epithelial-mesenchymal transition

\section{Introduction}

Esophageal cancer is one of the most aggressive cancers in the world. According to the latest epidemiological data, in 2018, the number of incidences of esophageal cancer and the number of death from esophageal cancer were reported to be 572,034 and 508,585 worldwide, respectively, which makes it the ninth and sixth highest rates for incidence and mortality among all the malignant tumors (1). Therefore, there is an immediate need to find more effective methods to diagnose, treat, and predict the prognosis of esophageal cancer.

Yes-associated protein (YAP), a candidate oncogene located on chromosome 11q22, is a negative regulator of the Hippo pathway, which has been previously reported as a tumor suppressor pathway in Drosophila and mammals $(2,3)$. Previous studies suggest that the Hippo-Yap pathway plays an important role in the genesis and progression of tumors $(4,5)$. Increased YAP expression has been associated with the progression of several human cancers, including cervical cancer (6), pancreatic ductal adenocarcinoma (7) and human urothelial carcinoma of the bladder (8). In addition, YAP overexpression is associated with poor prognosis in human urothelial carcinoma of the bladder (8), ovarian cancer (9), and colorectal cancer (10). Our previous studies have shown that YAP overexpression plays vital roles in the progression and metastasis of prostate and pancreatic cancer $(11,12)$. However, a previous study has reported that the overexpression of YAP was associated with poor overall survival (OS) in esophageal cancer in Japan (13). Further research is required to understand the role of the expression level of YAP in esophageal cancer and its importance in prognosis prediction.

Epithelial-mesenchymal transition (EMT) is a process described as the transition of cells from epithelial phenotype to mesenchymal phenotype and during this process cells gain more migratory and invasive properties (14). Although YAP has previously been reported to be associated with tumor metastasis via EMT in several tumors, including non-small cell lung cancer (15), breast cancer (16), pancreatic ductal adenocarcinoma (17), and hepatocellular carcinoma (18), its involvement in ESCC still remains unclear. There are no reports, so far, with regard to YAP regulation of tumor migration and invasion through EMT in ESCC. 
Since one previous study reported that downregulation of YAP inhibits proliferation and induces apoptosis in ESCC cells (19), the exact role of YAP in ESCC remains largely unclear. The present study aimed to investigate the role of YAP expression in tissue samples from patients with ESCC by performing a stratified analysis based on pathological TNM stage to provide further insights into the influence of YAP expression for prognosis of patients with ESCC, with respect to both OS and disease-free survival (DFS). Furthermore, small interfering RNA (siRNA) was transfected into Eca109 and Kyse150 cells and the effects of YAP inhibition on these ESCC cells was investigated to explore the underlying molecular mechanism.

\section{Materials and methods}

Patients and samples. A total of 107 paraffin-embedded tumor tissue samples from patients who underwent esophagectomy at Qilu Hospital of Shandong University (Jinan, China) were collected between January 2008 and October 2008. All cases were confirmed as ESCC by three people as stated in the immunohistochemical (IHC) analysis section. Samples were excluded from the study as follows: i) If the patient received radiation therapy or chemotherapy before surgery; ii) if the patient died or was untraceable during follow-up and iii) if the patient was diagnosed with more than one primary tumor. The clinicopathological data, including age, sex, history of smoking and alcohol consumption, differentiation degree, invasion depth ( $\mathrm{T}$ stage), lymph node metastasis ( $\mathrm{N}$ stage), pathological TNM (pTNM) (20), and adjuvant treatment after surgery were obtained from the clinical or pathological records. The present study was approved by The Ethics Committee of Qilu Hospital. All patients in the study were anonymous and provided written informed consent.

Follow-up. In the first 2 years after surgery, patients were contacted by telephone every 3 months to enquire about their recovery and assess the level of recurrence, if any. More detailed instructions were provided according to tumor progression if recurrence occurred. After 2 years, information regarding the patients was collected every 6 months until November 2013, unless they were either untraceable or had died.

IHC analysis. Tumor tissues of patients with ESCC were fixed in $10 \%$ formalin for $12 \mathrm{~h}$ at $4^{\circ} \mathrm{C}$ and embedded in paraffin. The paraffin-embedded tissues were cut into $5 \mu \mathrm{m}$ thick sections, and IHC staining was performed using the Streptavidin-BiotinComplex kit according to the manufacturer's protocol (cat. no. SA1022; Wuhan Boster Biological Technology Co., Ltd.). Tissue sections were mounted on to the microslides and incubated for $1 \mathrm{~h}$ at $60^{\circ} \mathrm{C}$ before de-waxing in xylene and hydrated in graded concentrations of alcohol $(95,90,85,80$ and $75 \%)$. Then the sections were placed in a solution of sodium citrate $(\mathrm{pH} 6.0)$ and were heated to $93^{\circ} \mathrm{C}$, and maintained at $90^{\circ} \mathrm{C}$ for $15 \mathrm{~min}$ to retrieve the antigen. The solution was cooled to room temperature and $3 \% \mathrm{H}_{2} \mathrm{O}_{2}$ was subsequently added at room temperature for $10 \mathrm{~min}$, to block the non-specific protein binding sites and inactivate the endogenous peroxidase. After blocking with 5\% BSA (Wuhan Boster Biological Technology Co., Ltd.) for $20 \mathrm{~min}$ at room
Table I. Baseline characteristics of the 107 esophageal squamous cell carcinoma patients.

\begin{tabular}{|c|c|}
\hline Characteristics & Value, n (\%) \\
\hline \multicolumn{2}{|l|}{ Sex } \\
\hline Female & $20(18.7)$ \\
\hline Male & $87(81.3)$ \\
\hline \multicolumn{2}{|l|}{ Age } \\
\hline Mean \pm SD & $61.20 \pm 9.266$ \\
\hline Median, n (range) & $61(32-84)$ \\
\hline \multicolumn{2}{|l|}{ Smoking } \\
\hline Yes & $54(50.5)$ \\
\hline No & $53(49.5)$ \\
\hline \multicolumn{2}{|l|}{ Drinking } \\
\hline Yes & $49(45.8)$ \\
\hline No & $58(54.2)$ \\
\hline \multicolumn{2}{|l|}{ Differentiation degree } \\
\hline Well & $27(25.2)$ \\
\hline Middle & $55(51.4)$ \\
\hline Poor & $25(23.4)$ \\
\hline \multicolumn{2}{|l|}{ T stage } \\
\hline $\mathrm{T} 1$ & $4(3.7)$ \\
\hline $\mathrm{T} 2$ & $42(39.3)$ \\
\hline $\mathrm{T} 3$ & $56(52.3)$ \\
\hline $\mathrm{T} 4$ & $5(4.7)$ \\
\hline \multicolumn{2}{|l|}{$\mathrm{N}$ stage } \\
\hline N0 & $56(52.3)$ \\
\hline $\mathrm{N} 1-3$ & $51(47.7)$ \\
\hline \multicolumn{2}{|l|}{ pTNM stage } \\
\hline I & $5(4.7)$ \\
\hline III & $56(52.3)$ \\
\hline III & $46(43.0)$ \\
\hline
\end{tabular}

Follow-up time

Mean \pm SD

$43.20 \pm 22.83$

Median, n (range)

YAP expression

Low

$65(60.7)$

Over

$42(39.3)$

Adjuvant treatment

None

$63(58.9)$

Radiotherapy

$17(15.9)$

Chemotherapy

CRT

$18(16.8)$

CRT, radiochemotherapy; T stage, invasion depth; N stage, lymph node metastasis; pTNM, pathological TNM.

temperature, the sections were incubated overnight at $4^{\circ} \mathrm{C}$ with mouse polyclonal primary antibody against YAP (dilution 1:300; cat. no. 4912; Cell Signaling Technology, Inc.). Then, the sections were incubated with biotinylated goat anti-rabbit 

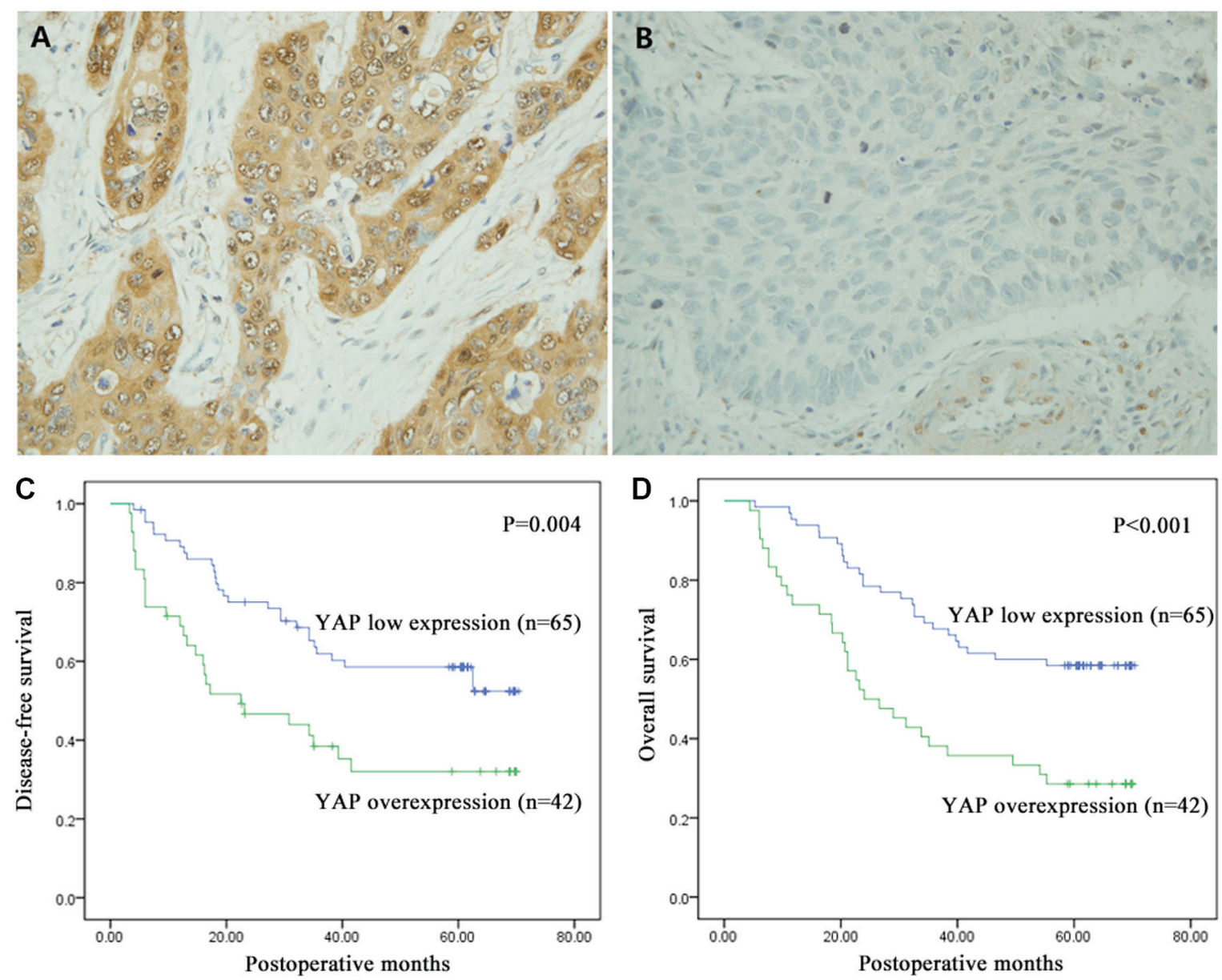

Figure 1. Immunohistochemical staining of YAP in esophageal squamous cell cancer tissues and Kaplan-Meier analysis and log-rank test of YAP expression for DFS and OS. (A) Overexpression and (B) low expression levels of YAP. YAP expression was localized to the cytoplasm of the cells. Magnification, $\mathrm{x} 400$. (C and D) Kaplan-Meier analysis and log-rank test of YAP for (C) DFS and (D) OS. YAP overexpression significantly predicted decreased DFS (P=0.004) and decreased OS $(\mathrm{P}<0.001)$. DFS, disease-free survival; YAP, yes-associated protein; OS, overall survival.

antibody from the kit for $20 \mathrm{~min}$ at $37^{\circ} \mathrm{C}$. Finally, the slides were counterstained with hematoxylin at $25^{\circ} \mathrm{C}$ for 2 min dehydrated in graded alcohol solution $(75,80,85,90,95$ and $100 \%)$ and xylene, and covered with coverslips using neutral balsam.

The IHC images were scored for positive staining intensity in five high-power fields using a light microscope (magnification, $\mathrm{x} 400$ ) independently by three people, including a pathologist and two authors of the current study who did not participate in the IHC staining (LZ and YJ). The intensity score was graded as follows: i) None, 0 ; ii) mild, 1; iii) moderate, 2; and iv) intense, 3 . The percentage of positive tumor cells was assessed according to the following patterns: i) No staining, 0 ; ii) $\leq 10 \%, 1$; iii) $10-50 \%, 2$; iv) and $>50 \% 3$. The staining intensity was assessed as follows: i) Negative, 0 ; ii) weak, 1 ; iii) moderate, 2 ; and iv) strong, 3 . The final score was the combination of the intensity score and the positive percentage score for each section. A score of 1-5 was designated as low expression and an overall score of 6-9 was designated as high expression of YAP in ESCC tissues (21).

Cell culture and transfection. Human esophageal squamous carcinoma cell lines Eca109, TE-10 and TE-11 were obtained from Procell Life Science \& Technology Co., Ltd. The Kyse150 cell line was purchased from Cell Bank, Shanghai Institutes for Biological Sciences, Chinese Academy of Sciences, and Kyse140 was kindly provided by Professor Xinyuan Guan (Department of Clinical Oncology, Li Ka Shing Faculty of Medicine, University of Hong Kong, Hong Kong, China). The cells were grown in RPMI-1640 medium (Gibco; Thermo Fisher Scientific, Inc.), and supplemented with $10 \%$ FBS (Gibco; Thermo Fisher Scientific, Inc.) and 1\% penicillin-streptomycin antibiotic solution. Human esophageal squamous carcinoma Eca109 cells were cultured in RPMI-1640 supplemented with only $10 \%$ FBS. The cells were incubated at $37^{\circ} \mathrm{C}$ in a humidified incubator containing $5 \% \mathrm{CO}_{2}$.

Eca109 and Kyse150 cell lines were transfected with YAP-specific siRNA oligonucleotides synthesized by GenePharma using EndoFectin ${ }^{\mathrm{TM}}$ MAX (GeneCopoeia Inc.). YAP-specific siRNA oligonucleotides were synthesized according to the following target sequences: YAP\#1, 5'-CAG GTGATACTATCAACCAAA-3' and YAP\#2, 5'-GACCAA TAGCTCAGATCCTTT-3'. Non-targeting siRNA (silencer negative control siRNA, siNC, forward: 5'-CCCAUUCAU UGUUGUCACUTT-3', reverse: 5'-AGUGACAACAAUGAA UGGGTT-3') was also transfected into Eca109 and Kyse150 cell lines as the negative control. The final concentration of the siRNA used was $50 \mathrm{nM}$. After transfection for $48 \mathrm{~h}$, the cells were used in the subsequent experiment. 
Western blot analysis. After transfection for $48 \mathrm{~h}$, cells were lysed, and proteins were extracted using RIPA (cat. no. P0013C; Beyotime Institute of Biotechnology) and determined by a BCA protein assay. The proteins $(25 \mu \mathrm{g} / \mathrm{lane})$ were separated by SDS-PAGE (5\% gel for concentration and $10 \%$ gel for separation). Then, the separated proteins were transferred onto polyvinylidene difluoride membranes. The membrane was blocked with 5\% skimmed milk in TBST $(\mathrm{pH} 7.4)$ at room temperature for $1 \mathrm{~h}$, and incubated with primary antibodies against YAP (dilution 1:1,000), vimentin (dilution 1:1,000; cat. no. 5741; Cell Signaling Technology, Inc.), E-cadherin (dilution 1:1,000; cat. no. ab15148; Abcam), N-cadherin (dilution 1:1,000; cat. no. 22018-1-AP; ProteinTech Group, Inc.) and GAPDH (dilution 1:1,000; cat. no. sc-47724; Santa Cruz Biotechnology, Inc.) overnight at $4^{\circ} \mathrm{C}$, then incubated with horseradish peroxidase-conjugated goat anti-rabbit (cat. no. s0001) and goat anti-mouse (cat. no. s0002) immunoglobulin G secondary antibodies (diluted 1:5,000; Affinity Biosciences) for $1 \mathrm{~h}$ at $25^{\circ} \mathrm{C}$. Immunoreactivity was detected using an enhanced chemiluminescence reaction kit (Pierce, Thermo Fisher Scientific, Inc.) and the bands were quantified by densitometry using ImageJ software (version 1.8.0; National Institutes of Health). GAPDH was used as the loading control.

Transwell migration and invasion assay. ESCC cells were resuspended in serum-free RPMI-1640 medium and added to the upper chamber of Transwell inserts $(8-\mu \mathrm{m}$ pore size, 6.5-mm diameter; Costar; Corning, Inc.) at a density of $3.0 \times 10^{5}$ cell $/ \mathrm{ml}$. The lower chamber contained RPMI-1640 medium with 15\% FBS. After incubation for $24 \mathrm{~h}$, a cotton-tipped swab was used to swab the cells on the upper chamber. The migrated cells, which were attached to the lower surface of the membrane, were fixed with pure methanol for $30 \mathrm{~min}$ at $25^{\circ} \mathrm{C}$ and stained with $0.1 \%$ crystal violet (Sigma-Alrich; Merck KGaA) for $20 \mathrm{~min}$ at $25^{\circ} \mathrm{C}$. The numbers of migrated cells were counted ( 5 fields per filter) using an inverted light microscope at a magnification of x100 and the mean number was subsequently calculated. The experiments were performed in triplicate and repeated three times. The procedure for the Transwell invasion assay was similar to the migration assay except that the membrane was precoated with Matrigel (Corning, Inc.) and the time of incubation was increased to $36 \mathrm{~h}$.

Statistical analysis. $\chi^{2}$ test was performed to evaluate the association between YAP expression and clinicopathological factors in ESCC. Kaplan-Meier analysis and log-rank test was used to calculate the survival rate and assess the difference between the two subgroups (the YAP overexpression and YAP low expression groups), respectively. Cox regression model was used in univariate and multivariate analyses, to identify significant independent prognostic factors associated with ESCC. For cell experiments, the data are presented as the mean \pm standard deviation and three individual experiments were performed in triplicate. One-way analysis of variance followed by Tukey's post hoc test was used to compare the data from different groups. All statistical analyses were performed using SPSS v17.0 software (SPSS, Inc.). $\mathrm{P}<0.05$ was considered to indicate a statistically significant difference.
Table II. Association between clinicopathological features of esophageal squamous cell carcinoma and YAP expression in tumor tissues.

\begin{tabular}{|c|c|c|c|}
\hline \multirow{2}{*}{$\begin{array}{l}\text { Clinicopathological } \\
\text { features }\end{array}$} & \multicolumn{2}{|c|}{ YAP expression } & \multirow[b]{2}{*}{ P-value } \\
\hline & Low, $n=65$ & Over, $n=42$ & \\
\hline \multicolumn{4}{|l|}{ Age } \\
\hline$<60$ & 28 & 22 & \multirow[t]{2}{*}{0.428} \\
\hline$\geq 60$ & 37 & 20 & \\
\hline \multicolumn{4}{|l|}{ Sex } \\
\hline Male & 51 & 36 & \multirow[t]{2}{*}{0.449} \\
\hline Female & 14 & 6 & \\
\hline \multicolumn{4}{|l|}{ Smoking } \\
\hline No & 34 & 19 & \multirow[t]{2}{*}{0.554} \\
\hline Yes & 31 & 23 & \\
\hline \multicolumn{4}{|l|}{ Drinking } \\
\hline No & 35 & 23 & \multirow[t]{2}{*}{0.926} \\
\hline Yes & 30 & 19 & \\
\hline \multicolumn{4}{|l|}{ Differentiation } \\
\hline Well & 18 & 9 & \multirow[t]{3}{*}{0.146} \\
\hline Moderate & 36 & 19 & \\
\hline Poor & 11 & 14 & \\
\hline \multicolumn{4}{|l|}{ T stage } \\
\hline $\mathrm{T} 1-2$ & 31 & 15 & \multirow[t]{2}{*}{0.238} \\
\hline T3-4 & 34 & 27 & \\
\hline \multicolumn{4}{|l|}{$\mathrm{N}$ stage } \\
\hline NO & 40 & 16 & \multirow[t]{2}{*}{$0.029^{b}$} \\
\hline N1-3 & 25 & 26 & \\
\hline \multicolumn{4}{|l|}{ pTNM } \\
\hline I-II & 42 & 19 & \multirow[t]{2}{*}{0.071} \\
\hline III & 23 & 23 & \\
\hline \multicolumn{4}{|l|}{ Adjuvant treatment } \\
\hline None & 35 & 28 & \multirow[t]{4}{*}{0.417} \\
\hline Radiotherapy & 13 & 4 & \\
\hline Chemotherapy & 5 & 4 & \\
\hline CRT & 12 & 6 & \\
\hline
\end{tabular}

${ }^{\mathrm{a}} \chi^{2}$ test. ${ }^{\mathrm{b}} \mathrm{P}<0.05$. CRT, radiochemotherapy; T stage, invasion depth; $\mathrm{N}$ stage, lymph node metastasis; pTNM, pathological TNM.

\section{Results}

Clinicopathological characteristics of patients with ESCC. Clinicopathological characteristics of the 107 patients with ESCC are shown in Table I. Out of the 107 patients, a total of 20 $(18.7 \%)$ were females and $87(81.3 \%)$ were males, with a median age of 61 years, ranging from 32 to 84 years. A total of 54 (50.5\%) patients had a former or current cigarette smoking history and $49(45.8 \%)$ had a history of alcohol consumption. The median follow-up time was 49.50 months (range, 4.40-0.40 months).

YAP expression level in ESCC tissues. YAP expression level in the tumor tissues was investigated using IHC staining and 

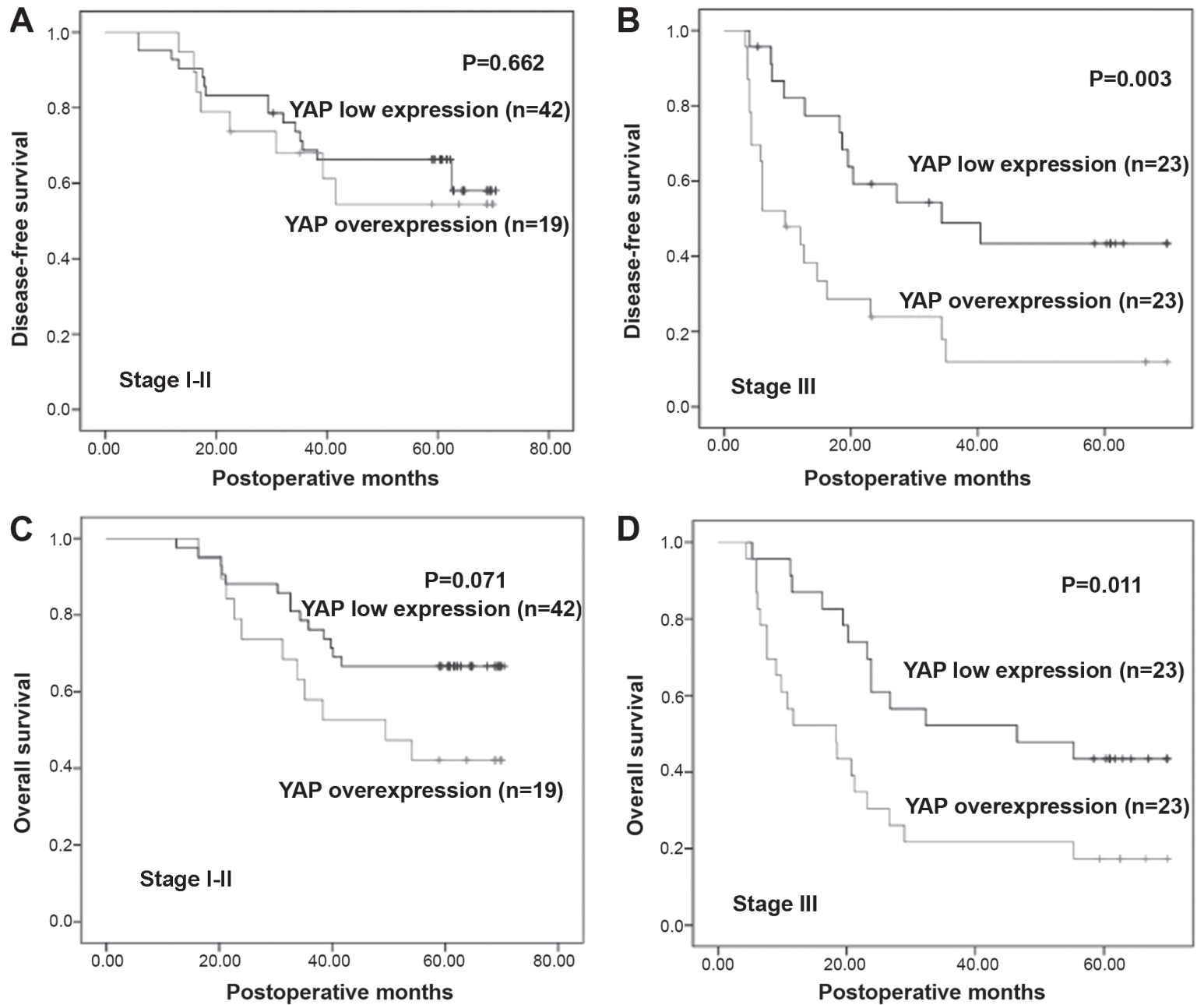

Figure 2. Kaplan-Meier analysis and log-rank test of YAP in subgroups of pTNM stage. (A and B) Kaplan-Meier curves for DFS stratified according to pTNM stage. YAP overexpression was associated with DFS in patients with stage III ESCC ( $\mathrm{P}=0.003)$, but not associated with stage I and II (P>0.05). (C and D) Kaplan-Meier curves for OS stratified by pTNM stage. YAP overexpression was associated with worse OS in ESCC patients with stage III ESCC $(\mathrm{P}=0.011)$, and not in stage I and II ( $\mathrm{P}>0.05)$. YAP, yes-associated protein; ESCC, esophageal squamous cell cancer; pTNM, pathological TNM.

shown in brown. As shown in Fig. 1A and B, YAP was mainly positively expressed in the cytoplasm, but it was also observed in the nucleus. IHC staining showed that YAP was overexpressed in $39.3 \%(42 / 107)$ of the samples and its expression was low in $60.7 \%(65 / 107)$ of the samples.

The association of YAP expression with clinicopathological features. To better understand the role of YAP expression level in the progression of ESCC, the data was analyzed using $\chi^{2}$ test. Overexpression of YAP was significantly associated with increased $\mathrm{N}$ stage of ESCC $(\mathrm{P}=0.029)$. However, there were no significant associations with the other clinicopathological features ( $\mathrm{P}>0.05$; Table II).

The prognostic value of YAP expression in ESCC. The mean survival time of all 107 patients was $43.20 \pm 22.83$ months (range 4.40-70.40 months). Kaplan-Meier analysis was performed along with log-rank test to investigate the relationship between YAP expression and prognosis. Compared to low expression of YAP, its overexpression was significantly associated with decreased DFS $(\mathrm{P}=0.004)$ and $\mathrm{OS}(\mathrm{P}<0.001$; Fig. 1C and D). Furthermore, the prognostic significance of
YAP expression in patient subgroups stratified by pTNM stage (I and II vs. III) was also investigated, and the results revealed significant associations between YAP overexpression and poor survival in patients with late stage ESCC, but not in early stage ESCC (I and II; Fig. 2).

Univariate and multivariate survival analyses. To further identify the role of YAP expression, univariate and multivariate analyses were performed. Univariate analysis showed that age, $\mathrm{N}$ stage, pTNM and YAP expression were statistically significantly associated with OS and DFS $(\mathrm{P}<0.05)$. Since previous studies reported that sex, smoking status, alcohol consumption, $\mathrm{T}$ stage, differentiation degree, and adjuvant treatment might play critical roles in prognosis of ESCC patients $(22,23)$, all factors were included in the multivariate analysis, and the result indicated YAP overexpression is an independent prognostic factor for OS (HR, 2.727; 95\% CI 1.556-4.780; $\mathrm{P}<0.001)$ and DFS (HR, 2.161; 95\% CI, 1.223-3.818; $\mathrm{P}=0.008$; Table III).

Expression analysis of YAP protein in ESCC cell lines. Five common ESCC cell lines (TE-10, TE-11, Kyse150, Kyse140 
Table III. Univariate and multivariate analysis of prognostic variables for esophageal squamous cell carcinoma.

\begin{tabular}{|c|c|c|c|c|c|c|}
\hline \multirow[b]{3}{*}{ Variable } & \multicolumn{3}{|c|}{ Overall survival } & \multicolumn{3}{|c|}{ Disease-free survival } \\
\hline & \multirow{2}{*}{$\begin{array}{l}\text { Univariate } \\
\text { analysis } \\
\text { P-value }\end{array}$} & \multicolumn{2}{|c|}{ Multivariate analysis } & \multicolumn{2}{|c|}{ Univariate analysis } & \multirow{2}{*}{$\begin{array}{c}\begin{array}{c}\text { Multivariate } \\
\text { analysis }\end{array} \\
\text { P-value }\end{array}$} \\
\hline & & $\mathrm{HR}(95 \% \mathrm{CI})$ & P-value & P-value & HR $(95 \% \mathrm{CI})$ & \\
\hline Sex & & 1.528 & & & 0.699 & \\
\hline Male vs. female & 0.598 & $(0.670-3.484)$ & 0.313 & 0.999 & $(0.303-1.613)$ & 0.402 \\
\hline Age & & 0.559 & & & 0.941 & \\
\hline$<60$ vs. $\geq 60$ & $0.030^{\mathrm{a}}$ & $(0.318-0.981)$ & $0.043^{\mathrm{a}}$ & 0.585 & $(0.533-1.662)$ & 0.835 \\
\hline Smoking & & 0.931 & & & 0.639 & \\
\hline Yes vs. no & 0.921 & $(0.469-1.847)$ & 0.838 & 0.212 & $(0.335-1.218)$ & 0.174 \\
\hline Drinking & & 1.910 & & & 0.951 & \\
\hline Yes vs. no & 0.282 & $(0.957-3.812)$ & 0.067 & 0.762 & $(0.488-1.851)$ & 0.882 \\
\hline $\mathrm{T}$ stage & & 0.872 & & & 0.785 & \\
\hline T1-2 vs. T3 -4 & 0.445 & $(0.466-1.631)$ & 0.668 & 0.452 & $(0.422-1.458)$ & 0.443 \\
\hline $\mathrm{N}$ stage & & 1.530 & & & 1.035 & \\
\hline N0 vs. N1-3 & $<0.001^{\mathrm{a}}$ & $(0.533-4.395)$ & 0.430 & $0.001^{\mathrm{a}}$ & $(0.365-2,937)$ & 0.948 \\
\hline Differentiation & & 0.783 & & & 0.885 & \\
\hline Well vs. moderate vs. poor & 0.658 & $(0.526-1.165)$ & 0.227 & 0.915 & $(0.595-1.316)$ & 0.545 \\
\hline pTNM & & 1.805 & & & 3.108 & \\
\hline I-II vs. III & $<0.001^{\mathrm{a}}$ & $(0.608-5.357)$ & 0.287 & $<0.001^{\mathrm{a}}$ & $(1.038-9.310)$ & $0.043^{\mathrm{a}}$ \\
\hline YAP expression & & 2.727 & & & 2.161 & \\
\hline Low vs. over & $0.001^{\mathrm{a}}$ & $(1.556-4.780)$ & $<0.001^{\mathrm{a}}$ & $0.005^{\mathrm{a}}$ & $(1.223-3.818)$ & $0.008^{\mathrm{a}}$ \\
\hline CRT & & 0.974 & & & 0.907 & \\
\hline $\begin{array}{l}\text { None vs. RT vs. } \\
\text { CT vs. RT+CT }\end{array}$ & 0.785 & $(0.768-1.237)$ & 0.831 & 0.620 & $(0.708-1.163)$ & 0.443 \\
\hline
\end{tabular}

${ }^{a} \mathrm{P}<0.05$. HR, hazard ratio; CI, confidence interval; RT, radiotherapy; CT, chemotherapy; CRT, Radiochemotherapy; T stage, invasion depth; N stage, lymph node metastasis; pTNM, pathological TNM.

and Eca109) were used to screen for cell lines with high YAP expression. Since Kyse150 and Eca109 expressed higher levels of YAP than other three cell lines, they were selected for further experiments. The results of the screening by western blot are shown in Fig. S1.

Downregulation of YAP protein expression inhibits the expression of EMT markers in ESCC. To investigate the function of YAP in ESCC, siRNA was used to specifically knockdown YAP expression in ESCC cells. YAP siRNA and siNC were successfully transfected into the cells, and western blot analysis was performed. The analysis showed that YAP expression was successfully downregulated by siYAP but not by siNC, at the protein level (Fig. 3). Western blot analysis was also performed to detect levels of EMT-related proteins. Compared with the control group, levels of vimentin and $\mathrm{N}$-cadherin were significantly reduced when YAP was downregulated, while that of E-cadherin was significantly increased, in both cell lines (Eca109 and Kyse150). Western blotting results showed that YAP could regulate levels of EMT-related proteins in ESCC cells.
Downregulation of YAP inhibits cell migration and invasion of ESCC cells. To identify whether YAP affects the ability of cell migration and invasion in Eca109 and Kyse150 cells, transwell migration and invasion assays were performed. Compared with the control group, cell migration and invasion were both significantly decreased by the downregulation of YAP after siYAP\#1 and siYAP\#2 transfection $(\mathrm{P}<0.001)$, in both cell lines. However, no significant difference was found between the control and siNC groups (Fig. 4).

\section{Discussion}

The oncogenic role of Hippo-YAP signaling pathway has been reported in various human malignancies $(6-9,24)$. Our previous research revealed that YAP overexpression in prostate and pancreatic cancers promoted tumor progression and metastasis $(11,12)$. However, there are few reports regarding YAP expression in ESCC. In the present study, the level of YAP expression was detected in ESCC tissues and its association with clinicopathological features was analyzed. The analysis showed that YAP expression was only associated with $\mathrm{N}$ stage 
A

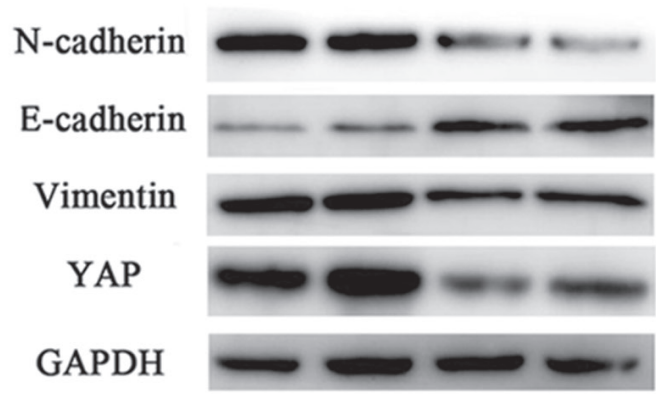

Con SiNC SiYAP\#1 SiYAP\#2
Kyse150

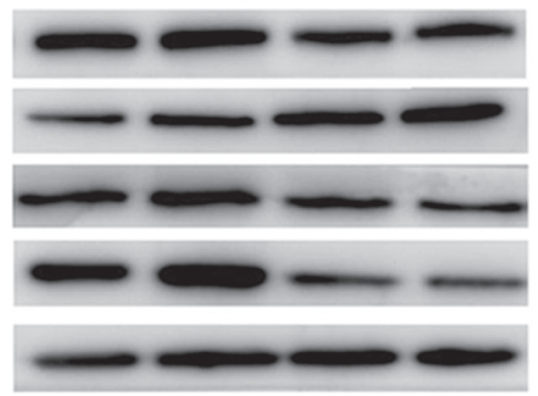

Con SiNC SiYAP\#1SiYAP\#2
B
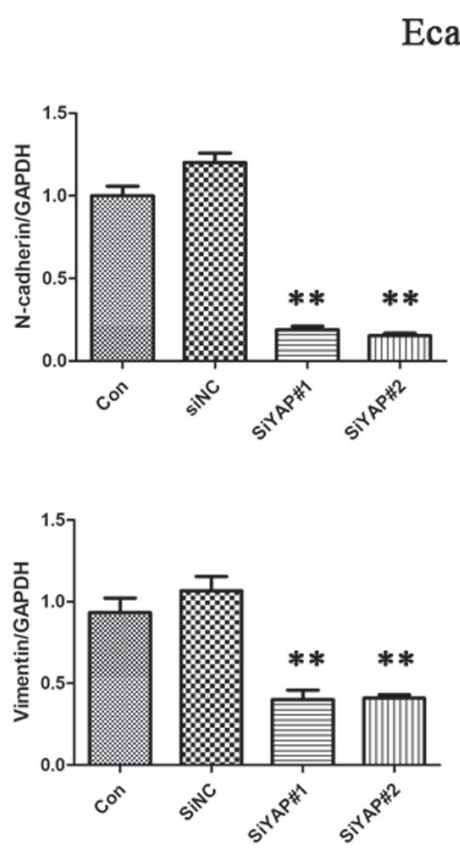

Eca109
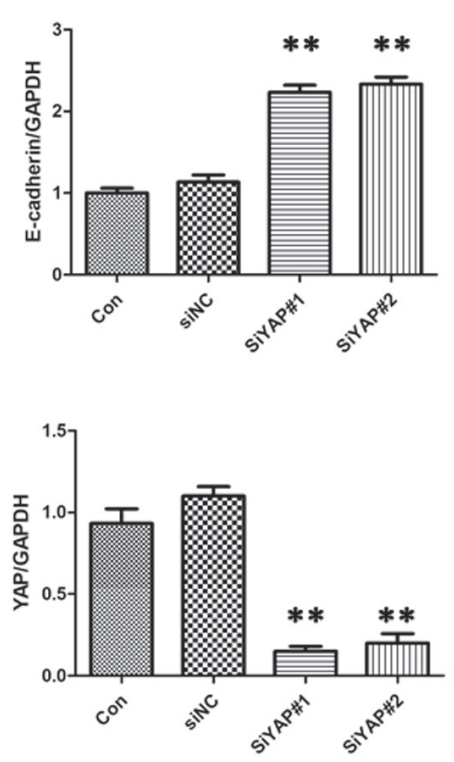

C
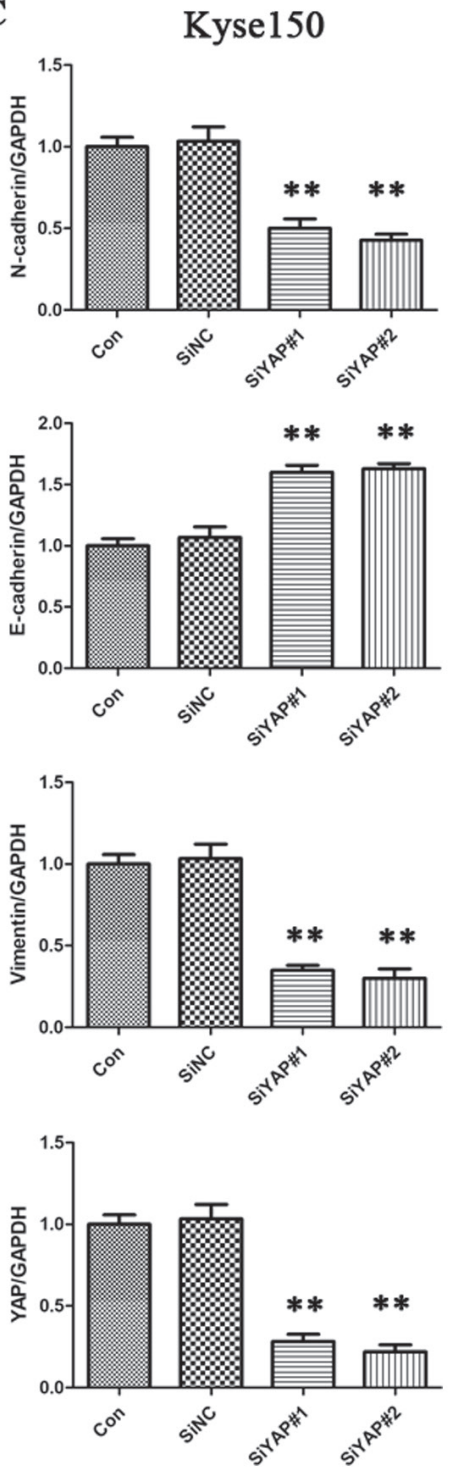

Figure 3. YAP is associated with the expression of epithelial-mesenchymal transition markers in esophageal squamous cell cancer cell lines. (A) Representative immunoblots and quantitative analysis of the expression levels of vimentin, N-cadherin, E-cadherin and YAP after siYAP transfection in (B) Eca109 and (C) Kyse150 cells. Data are presented as the mean \pm standard error of the mean, and this procedure was performed in triplicate. ${ }^{* *} \mathrm{P}<0.01$ vs. control group. YAP, yes-associated protein; si, small interfering; NC, negative control; Con, control.

of tumor, however this could be due to the small sample size. Consistent with observations by previous studies, the results also indicate that compared with low expression of YAP, overexpression of YAP predicted poorer OS and DFS (6-9,24). Different statistical methods suggested that YAP expression level could serve as an independent factor for predicting poor prognosis, especially in patients with stage III ESCC, when stratified based on pTNM stage.

The mechanisms underlying YAP-regulated progression and prognosis of ESCC have not been verified. YAP was found to aid esophageal cancer cells develop cancer stem cell-like properties through driving SRY-box 9 expression (21). There is a previous report suggesting that downregulation of YAP inhibits proliferation and induces apoptosis in Eca109 cells (19). Other possible mechanisms of YAP regulation have been reported in other cell lines and tumors. It has been proven that YAP oncoprotein can overcome inhibition caused by high cell-contact and promote cell proliferation in NIH-3T3 cells and MCF10A human breast epithelial cell line (25). YAP overexpression was further confirmed to trigger EMT in MCF10A cells (3). In papillary thyroid cancer B-CPAP and KI cell lines, knockdown of YAP was found to inhibit the proliferation, migration, and invasion, and cause cell cycle arrest and induce autophagy of tumor cells (24). In addition, in prostate cancer, YAP acted as a regulator of cell motility, invasion, castration-resistant growth and hence might be a potential therapeutic target (11). In gastric cancer, it was found that Netrin-1 promotes metastasis of gastric cancer by upregulating YAP expression via its transmembrane receptor neogenin (26). In addition, YAP could regulate the initiation and progression of cervical (6) and ovarian cancer (9) through the ErbB signaling pathway. Previous studies have reported that activated YAP could cause the upregulation of TGF- $\alpha$, amphiregulin, and epidermal growth factor receptor, facilitating the formation of a positive signaling loop to promote cervical and ovarian cancer cell proliferation $(6,9)$. There are 

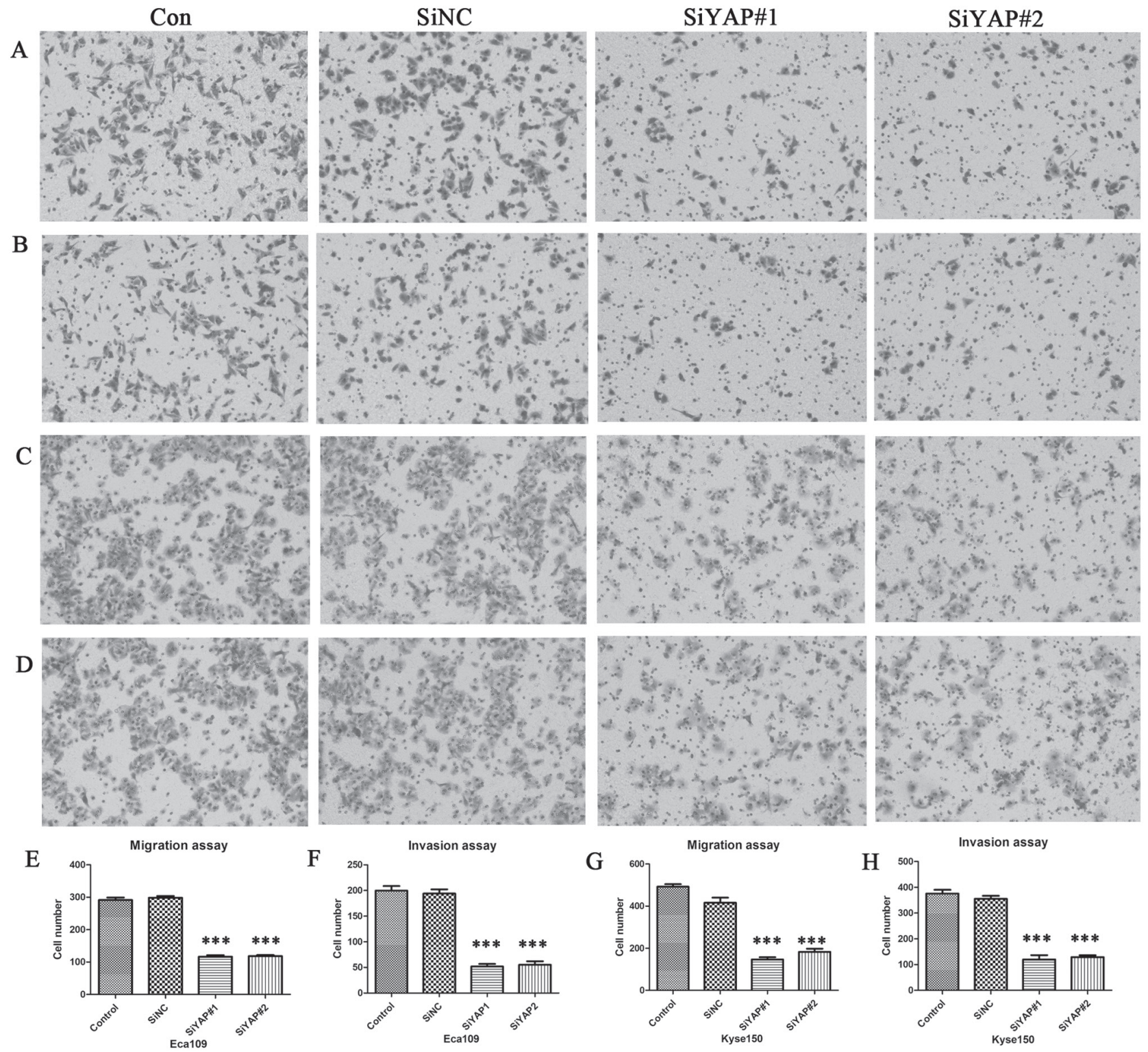

G

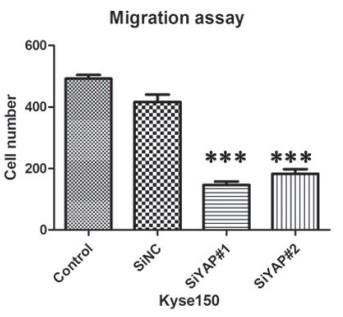

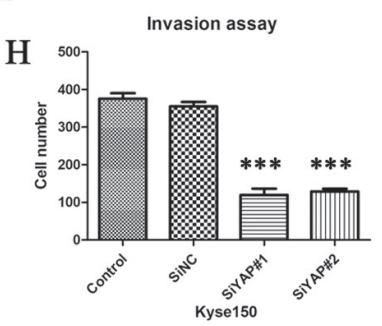

Figure 4. YAP regulates cell migration and invasion in vitro. Cell images of migration for (A) Eca109 and (C) Kyse150 cells and of invasion for (B) Eca109 and (D) Kyse150 cells stained with crystal violet (magnification, x100). (E-H) The number of migrated and invasive cells in the YAP knockdown group was significantly less compared with those in the control, in both Eca109 and Kyse150 cells. ${ }^{* * * *} \mathrm{P}<0.001$ vs. control group.

reports regarding the tumor suppressive effect of YAP, either by inhibiting WNT signaling (27) or by triggering DNA damage-induced apoptosis (28). Studies have shown that the YAP signaling pathway was associated with EMT (15-18). Nevertheless, the mechanism of YAP overexpression in ESCC tissues and further influence on the prognosis remain to be elucidated. The present study presents the potential mechanism of YAP regulation in ESCC, possibly through EMT.

There are several limitations in the present study. First, as a retrospective cohort study, the sample number was small, which might have influenced the reliability of the results. Second, there could have been more suitable cutoff values for determining the overexpression and the reduced expression of YAP, which could improve predicting the prognosis. Third, more detailed elucidation of the mechanism of YAP expression affecting the prognosis remains to be discovered. Further studies are required to propose suitable methods to target the elevated expression of YAP and thereby improve the prognosis.

\section{Acknowledgements}

The authors would like to thank Dr. Xinyuan Guan (Department of Clinical Oncology Cancer Research Center, University of Hong Kong, Hong Kong, China) for offering us the ESCC cell line.

\section{Funding}

The present study was supported by National Natural Science Foundation of China (grant nos. 81773228, 81572958 and 81602007), Natural Science Foundation of Shandong Province (grant no. ZR2016HB68), Nanshan Project of Yantai for Shandong University (grant no. 2014QLKY31) and Key 
Research and Development Program of Shandong Province (grant no. 2017GSF18153).

\section{Availability of data and materials}

The datasets used and/or analyzed during the current study are available from the corresponding author upon reasonable request.

\section{Authors' contributions}

YQ, LZ, JW and YJ performed the experiments, analysis and wrote the manuscript. PC, CW and WY generated the data and performed the analyses. ZW, QS, BT and YC interpreted the data, drafted the manuscript and made critical revisions. All authors discussed the results and reviewed the manuscript.

\section{Ethics approval and consent to participate}

The present study was approved by The Ethics Committee of Qilu Hospital. All the patients in the study were anonymous and provided written informed consent.

\section{Patient consent for publication}

Not applicable.

\section{Competing interests}

The authors declare that they have no competing interests.

\section{References}

1. Bray F, Ferlay J, Soerjomataram I, Siegel RL, Torre LA and Jemal A: Global cancer statistics 2018: GLOBOCAN estimates of incidence and mortality worldwide for 36 cancers in 185 countries. CA Cancer J Clin 68: 394-424, 2018.

2. Zender L, Spector MS, Xue W, Flemming P, Cordon-Cardo C, Silke J, Fan ST, Luk JM, Wigler M, Hannon GJ, et al: Identification and validation of oncogenes in liver cancer using an integrative oncogenomic approach. Cell 125: 1253-1267, 2006

3. Overholtzer M, Zhang J, Smolen GA, Muir B, Li W, Sgroi DC, Deng CX, Brugge JS and Haber DA: Transforming properties of YAP, a candidate oncogene on the chromosome 11q22 amplicon. Proc Natl Acad Sci USA 103: 12405-12410, 2006.

4. Pan D: The hippo signaling pathway in development and cancer. Dev Cell 19: 491-505, 2010.

5. Moroishi T, Hansen CG and Guan KL: The emerging roles of YAP and TAZ in cancer. Nat Rev Cancer 15: 73-79, 2015.

6. He C, Mao D, Hua G, Lv X, Chen X, Angeletti PC, Dong J, Remmenga SW, Rodabaugh KJ, Zhou J, et al: The Hippo/YAP pathway interacts with EGFR signaling and HPV oncoproteins to regulate cervical cancer progression. EMBO Mol Med 7: 1426-1449, 2015.

7. Zhang W, Nandakumar N, Shi Y, Manzano M, Smith A, Graham G, Gupta S, Vietsch EE, Laughlin SZ, Wadhwa M, et al: Downstream of mutant KRAS, the transcription regulator YAP is essential for neoplastic progression to pancreatic ductal adenocarcinoma. Sci Signal 7: ra42, 2014.

8. Liu JY, Li YH, Lin HX, Liao YJ, Mai SJ, Liu ZW, Zhang ZL, Jiang LJ, Zhang JX, Kung HF, et al: Overexpression of YAP 1 contributes to progressive features and poor prognosis of human urothelial carcinoma of the bladder. BMC Cancer 13: $349,2013$.

9. He C, Lv X, Hua G, Lele SM, Remmenga S, Dong J, Davis JS and Wang C: YAP forms autocrine loops with the ERBB pathway to regulate ovarian cancer initiation and progression. Oncogene 34: 6040-6054, 2015.
10. Wang L, Shi S, Guo Z, Zhang X, Han S, Yang A, Wen W and Zhu Q: Overexpression of YAP and TAZ Is an independent predictor of prognosis in colorectal cancer and related to the proliferation and metastasis of colon cancer cells. PLoS One 8: e65539, 2013.

11. Zhang L, Yang S, Chen X, Stauffer S, Yu F, Lele SM, Fu K, Datta K, Palermo N, Chen Y and Dong J: The hippo pathway effector YAP regulates motility, invasion, and castration-resistant growth of prostate cancer cells. Mol Cell Biol 35: 1350-1362, 2015.

12. Yang SP, Zhang L, Purohit V, Shukla SK, Chen X, Yu F, Fu K, Chen Y, Solheim J, Singh PK, et al: Active YAP promotes pancreatic cancer cell motility, invasion and tumorigenesis in a mitotic phosphorylation-dependent manner through LPAR3. Oncotarget 6: 36019-36031, 2015.

13. Muramatsu T, Imoto I, Matsui T, Kozaki K, Haruki S, Sudol M, Shimada Y, Tsuda H, Kawano $\mathrm{T}$ and Inazawa J: YAP is a candidate oncogene for esophageal squamous cell carcinoma. Carcinogenesis 32: 389-398, 2011.

14. Chen T, You Y, Jiang H and Wang ZZ: Epithelial-mesenchymal transition (EMT): A biological process in the development, stem cell differentiation, and tumorigenesis. J Cell Physiol 232: 3261-3272, 2017.

15. Jin D, Wu Y, Shao C, Gao Y, Wang D and Guo J: Norcantharidin reverses cisplatin resistance and inhibits the epithelial mesenchymal transition of human nonsmall lung cancer cells by regulating the YAP pathway. Oncol Rep 40: 609-620, 2018.

16. Kulkarni M, Tan TZ, Syed Sulaiman NB, Lamar JM, Bansal P, Cui J, Qiao Y and Ito Y: RUNX1 and RUNX3 protect against YAP-mediated EMT, stem-ness and shorter survival outcomes in breast cancer. Oncotarget 9: 14175-14192, 2018.

17. Thongon N, Castiglioni I, Zucal C, Latorre E, D'Agostino V, Bauer I, Pancher M, Ballestrero A, Feldmann G, Nencioni A and Provenzani A: The GSK3 $\beta$ inhibitor BIS I reverts YAP-dependent EMT signature in PDAC cell lines by decreasing SMADs expression level. Oncotarget 7: 26551-26566, 2016.

18. Yu S, Jing L, Yin XR, Wang MC, Chen YM, Guo Y, Nan KJ and Han LL: MiR-195 suppresses the metastasis and epithelial-mesenchymal transition of hepatocellular carcinoma by inhibiting YAP. Oncotarget 8: 99757-99771, 2017.

19. Cui M and Li Z: Downregulation of YAP inhibits proliferation and induces apoptosis in Eca-109 cells. Exp Ther Med 15: 1048-1052, 2018.

20. Rice TW, Ishwaran H, Ferguson MK, Blackstone EH and Goldstraw P: Cancer of the Esophagus and Esophagogastric Junction: An Eighth Edition Staging Primer. J Thorac Oncol 12: 36-42, 2017.

21. Song S, Ajani JA, Honjo S, Maru DM, Chen Q, Scott AW, Heallen TR, Xiao L, Hofstetter WL, Weston B, et al: Hippo coactivator YAP1 upregulates SOX9 and endows esophageal cancer cells with stem-like properties. Cancer Res 74: 4170-4182, 2014

22. Lin WC, Ding YF, Hsu HL, Chang JH, Yuan KS, Wu ATH, Chow JM, Chang CL, Chen SU and Wu SY: Value and application of trimodality therapy or definitive concurrent chemoradiotherapy in thoracic esophageal squamous cell carcinoma. Cancer 123 : 3904-3915, 2017.

23. Liu B, Cheng B, Wang C, Chen $\mathrm{P}$ and Cheng Y: The prognostic significance of metabolic syndrome and weight loss in esophageal squamous cell carcinoma. Sci Rep 8: 10101, 2018.

24. Liu Z, Zeng W, Wang S, Zhao X, Guo Y, Yu P, Yin X, Liu C and Huang T: A potential role for the Hippo pathway protein, YAP, in controlling proliferation, cell cycle progression, and autophagy in BCPAP and KI thyroid papillary carcinoma cells. Am J Transl Res 9: 3212-3223, 2017.

25. Zhao B, Wei X, Li W, Udan RS, Yang Q, Kim J, Xie J, Ikenoue T, $\mathrm{Yu} \mathrm{J}, \mathrm{Li} \mathrm{L}$, et al: Inactivation of YAP oncoprotein by the Hippo pathway is involved in cell contact inhibition and tissue growth control. Genes Dev 21: 2747-2761, 2007.

26. Yin K, Dang S, Cui L, Fan X, Xie R, Qu J, Shang M and Chen J: Corrigendum to 'Netrin-1 promotes metastasis of gastric cancer by regulating YAP activity' [Biochem. Biophys. Res. Commun.496 (1) (2018 Jan 29) 76-82]. Biochem Biophys Res Commun 498: 262, 2018.

27. Attisano L and Wrana JL: Signal integration in TGF- $\beta$, WNT, and Hippo pathways. F1000Prime Rep 5: 17, 2013.

28. Cottini F, Hideshima T, Xu C, Sattler M, Dori M, Agnelli L, ten Hacken E, Bertilaccio MT, Antonini E, Neri A, et al: Rescue of Hippo coactivator YAP1 triggers DNA damage-induced apoptosis in hematological cancers. Nat Med 20: 599-606, 2014.

This work is licensed under a Creative Commons Attribution-NonCommercial-NoDerivatives 4.0 International (CC BY-NC-ND 4.0) License. 